\title{
Asthma management at discharge from the emergency department: A descriptive study
}

\author{
Pascale Gervais B Pharm MSc ${ }^{1}$, Isabelle Larouche B Pharm MSc ${ }^{1}$, Lucie Blais PhD², \\ Anne Fillion B Pharm MSc ${ }^{1}$, Marie-France Beauchesne Pharm D ${ }^{1,2}$
}

P Gervais, I Larouche, L Blais, A Fillion, M-F Beauchesne. Asthma management at discharge from the emergency department: A descriptive study. Can Respir J 2005;12(4):219-222.

BACKGROUND: The management of asthma remains suboptimal despite the publication of Canadian asthma guidelines in 1999. OBJECTIVES AND METHODS: A descriptive study was conducted to estimate the proportion of patients admitted to the emergency department (ED) for an asthma exacerbation who received a management plan at discharge that was in accordance with seven criteria stated in the Canadian asthma guidelines. The present study took place in two tertiary care hospitals in Montreal, Quebec.

RESULTS: A total of 37 patients were enrolled. Three (8\%) patients received a management plan at discharge that was in accordance with all seven criteria. Inhaled corticosteroids and oral corticosteroids were prescribed at discharge for 29 (78\%) and 35 (95\%) patients, respectively. Minimal asthma education was provided for $29(78 \%)$ patients and a medical follow-up was recommended to $22(60 \%)$ patients. Airflow obstruction was evaluated at discharge for only $20(54 \%)$ patients.

CONCLUSION: Overall, asthma management at discharge from the ED was generally not in accordance with the 1999 Canadian asthma guidelines. A standardized management plan should be implemented in the ED to improve the care of patients with asthma exacerbations.

Key Words: Acute exacerbations of asthma; Asthma management; Canadian asthma guidelines; Emergency department

A pproximately 2.2 million Canadians have asthma, and the prevalence of this disease was estimated to be $7.8 \%$ in 1996 (1). A survey published in 1999 (2) indicated that 57\% of patients with asthma do not have adequate control of their disease based on the criteria stated in the 1999 Canadian asthma guidelines (3). Some patients with asthma have to limit their daily activities and seek health care services frequently. In the late 1990s, the total costs associated with asthma were over $\$ 600$ million (4). It was estimated that $28 \%$ of patients with asthma had visited the emergency department (ED) in 1999 and that $78 \%$ of these visits were attributable to poor asthma control (2). According to some studies $(2,5)$, in general, asthma management remains suboptimal despite the publication of Canadian asthma guidelines in 1999. Studies (5-8) have shown that in many health care centres, the management of asthma is not in accordance with these guidelines. More specifically, a study conducted in Canada by Reid et al (6) demonstrated that $74 \%$ of patients with asthma received a prescription for an inhaled corticosteroid (ICS) at discharge

\section{Prise en charge de l'asthme au départ des urgences : Étude descriptive}

\begin{abstract}
HISTORIQUE : La prise en charge de l'asthme reste insuffisante malgré la publication des Directives canadiennes pour le traitement de l'asthme en 1999

OBJECTIFS ET MÉTHODES : Une étude descriptive a été entreprise afin d'évaluer la proportion de patients admis aux urgences pour une crise d'asthme qui avaient reçu un plan de traitement à leur sortie, conformément aux sept critères énoncés dans les Directives canadiennes pour le traitement de l'asthme. La présente étude s'est déroulée à Montréal, au Québec, dans deux centres hospitaliers de soins tertiaires.

RÉSULTATS : En tout, 37 patients ont été admis à l'étude. Trois (8\%) patients ont reçu un plan de traitement concordant avec les sept critères au moment de leur départ des urgences. Des ordonnances de corticostéroïdes par inhalation et oraux avaient été remises respectivement à 29 (78 \%) et à 35 (95\%) patients au moment de leur congé. Un enseignement minime sur l'asthme a été fourni à $29(78 \%)$ patients et un suivi médical avait été recommandé à $22(60 \%)$ patients. L'obstruction respiratoire n'a été évaluée que chez 20 (54\%) patients au moment où ils quittaient le service des urgences.

CONCLUSION : Dans l'ensemble, la prise en charge de l'asthme chez les patients à leur départ des urgences ne s'est pas révélée conforme aux Directives canadiennes pour le traitement de l'asthme de 1999. Les urgences devraient adopter un plan standardisé de prise en charge de l'asthme à remettre au patient au moment où il reçoit son congé après une crise d'asthme.
\end{abstract}

from the ED and that a medical follow-up was planned in only $37 \%$ of patients.

The main objective of the present study was to estimate the proportion of patients admitted to the ED for an asthma exacerbation that received a management plan at discharge that was in accordance with seven criteria from the 1999 Canadian asthma guidelines. We also determined the proportion of patients who were referred to an asthma education centre and the proportion of these patients that attended their appointments.

\section{METHODS}

The present descriptive study was conducted in the EDs of two tertiary care hospitals in Montreal, Quebec, between October 29, 2001, and April 30, 2002. The study protocol was approved by the ethics committee of the Hôpital du Sacré-Coeur de Montréal (Montreal, Quebec) and participants were required to provide written informed consent. Patients included in the present study were admitted to the ED for an asthma exacerbation, were 14 years of age or older, and had to speak and understand French or English.

\footnotetext{
${ }^{1}$ Hôpital du Sacré-Cour de Montréal; ${ }^{2}$ University of Montreal, Montreal, Quebec
}

Correspondence: Marie-France Beauchesne, Pharmacy, Hôpital du Sacré-Cour de Montréal, 5400 Boulevard Gouin Ouest, Montreal, Quebec

H4J 1C5. Telephone 514-338-2222 ext 2666, fax 514-338-3200, e-mail marie-France.beauchesne@umontreal.ca 


\section{TABLE 1}

Baseline characteristics of the patients $(n=37)$

\begin{tabular}{|c|c|}
\hline Male sex, $\mathrm{n}(\%)$ & $17(46)$ \\
\hline Age (years; mean \pm SD) & $35 \pm 13$ \\
\hline \multicolumn{2}{|l|}{ Last degree completed, $\mathrm{n}(\%)$} \\
\hline Elementary and/or high school & $24(65)$ \\
\hline College and/or university & $13(35)$ \\
\hline Current smokers, $\mathrm{n}(\%)$ & $11(30)$ \\
\hline Second-hand smoke, n (\%) & $22(60)$ \\
\hline \multicolumn{2}{|l|}{ Comorbidities, n (\%) } \\
\hline Other respiratory illness & $2(5)$ \\
\hline Cardiovascular disease & $4(11)$ \\
\hline Psychiatric disease & $8(22)$ \\
\hline Endocrine disease & $3(8)$ \\
\hline Others & $8(22)$ \\
\hline Unknown & $12(32)$ \\
\hline \multicolumn{2}{|l|}{ Medication history, n (\%) } \\
\hline Short-acting beta ${ }_{2}$ agonist & $35(95)$ \\
\hline Inhaled corticosteroid & $27(73)$ \\
\hline Mean dose ${ }^{*} \pm S D, \mu g /$ day & $571 \pm 255$ \\
\hline Long-acting beta ${ }_{2}$ agonist & $8(22)$ \\
\hline Antileukotriene & $1(3)$ \\
\hline Oral corticosteroid & $1(3)$ \\
\hline Theophylline & 0 \\
\hline Duration of asthma, years (mean $\pm \mathrm{SD}$ ) & $15 \pm 10$ \\
\hline \multicolumn{2}{|l|}{ Severity of chronic asthma, $\mathrm{n}(\%)$} \\
\hline Very mild to mild & $9(24)$ \\
\hline Moderate & $17(46)$ \\
\hline Severe to very severe & $11(30)$ \\
\hline Patients who visited the asthma education centre, $n(\%)$ & $8(22)$ \\
\hline \multicolumn{2}{|l|}{ Indicators of asthma morbidity, $\mathrm{n}(\%)$} \\
\hline \multicolumn{2}{|l|}{ In the year preceding the emergency department visit } \\
\hline$\geq 1$ visit to the emergency department & $24(65)$ \\
\hline$\geq 1$ hospitalization & $10(27)$ \\
\hline$\geq 1$ unscheduled visit to a physician & $16(43)$ \\
\hline$\geq 1$ treatment of oral corticosteroid & $22(60)$ \\
\hline Number days of absenteeism (work or school) (mean \pm SD) & $5 \pm 7$ \\
\hline \multicolumn{2}{|l|}{ In the past } \\
\hline$\geq 1$ intubation & $3(8)$ \\
\hline$\geq$ Admission to the intensive care unit & $10(27)$ \\
\hline
\end{tabular}

${ }^{*}$ Fluticasone-chlorofluorocarbon equivalent

Patients who were hospitalized following their admission to the $\mathrm{ED}$ or who were readmitted in the $72 \mathrm{~h}$ following discharge were excluded.

Patients were interviewed in the ED during their stay and by telephone $72 \mathrm{~h}$ and one month following discharge. Their medical charts were also reviewed for data collection. The community pharmacist of each patient was contacted to collect information about the asthma medication prescribed and filled at the pharmacy. Finally, the asthma education centre database was consulted to retrieve information about patients' visits to the centre.

\section{Conformity criteria}

The following criteria from the 1999 Canadian asthma guidelines (3) were used to evaluate the management plan at discharge from the ED:

- measurement of airflow obstruction before discharge from the ED;
- prescription of an ICS at discharge (including a dosage increase or verbal advice to continue the ICS);

- prescription of an oral corticosteroid for patients who had a forced expiratory volume in $1 \mathrm{~s}$ or a peak expiratory flow measurement below $60 \%$ of the predicted value on admission to the ED;

- dosage of the oral corticosteroid between $30 \mathrm{mg} /$ day to $60 \mathrm{mg} /$ day (equivalent to prednisone);

- duration of treatment of the oral corticosteroid between seven and 14 days;

- asthma education provided to the patient in the ED; and

- advice regarding medical follow-up with a family doctor or a respiratory physician.

\section{Statistical analyses}

The proportion of patients (with 95\% CI) who at discharge from the ED had a management plan in accordance with the seven criteria from the 1999 Canadian asthma guidelines was estimated. In addition, the proportion for each individual criterion was estimated. The proportion of patients who were referred to and visited an asthma education centre was also calculated. Descriptive statistics were used to characterize patients included in the present study.

\section{RESULTS}

A total of 67 subjects who were initially treated at the ED for an asthma exacerbation were targeted to participate in the present study. Thirty-nine of the patients met the inclusion criteria and agreed to participate. Twenty-eight patients were excluded: 19 were hospitalized, seven refused to participate and two did not understand the English or French language. Two patients did not complete the second questionnaire; therefore, 37 patients were included in the study. Baseline characteristics of these patients are presented in Table 1.

The patients who completed the study had a mean age of 35 years and, on average, had had asthma for approximately 15 years. According to the medication histories of the patients (completed by a pharmacist with the patient and by the patient's community pharmacist), 35 (95\%) patients used a short-acting beta-agonist. In addition, 27 (73\%) patients had a prescription for regular use of an ICS; the mean dose prescribed was $571 \mu \mathrm{g} /$ day (in fluticasone-chlorofluorocarbon equivalent). Long-acting beta-agonists were used by eight (22\%) patients. Overall, nine (24\%) patients had mild asthma, 17 (46\%) had moderate asthma and 11 (30\%) had severe asthma according to the asthma severity criteria defined in the Canadian asthma guidelines (3) .

The characteristics of the asthma exacerbation that led to the ED visit are presented in Table 2. A severe asthma exacerbation was found in 21 (57\%) patients, while 11 (30\%) patients had a moderate exacerbation and no patient had a mild exacerbation. The severity of the exacerbations could not be determined for five (14\%) patients. The most frequent trigger reported by patients was a respiratory infection (23 patients $[62 \%])$. The average duration of stay in the ED was $18 \mathrm{~h}$. For $12(32 \%)$ patients, a consultation with a respiratory physician was requested by the ED physician.

The main results of the present study are outlined in Table 3. Only three of 37 patients (8\%) had a management plan that was in accordance with all seven criteria from the Canadian asthma guidelines. For two of these patients, there 
TABLE 2

Characteristics of the asthma exacerbations leading to the visit to the emergency department (ED) $(n=37)$

\begin{tabular}{lc}
\hline Severity of the exacerbation, $\mathrm{n}(\%)$ & $5(14)$ \\
Unknown & 0 \\
Mild (FEV 1 or PEF $>80 \%$ predicted) & $11(30)$ \\
Moderate $\left(\mathrm{FEV}_{1}\right.$ or PEF between $60 \%$ and $80 \%$ predicted) & $21(57)$ \\
Severe (FEV 1 or PEF <60\% predicted) & $58 \pm 13$ \\
PEF on admission to the ED, Mean \% of the predicted value $\pm \mathrm{SD}$ & $45 \pm 15$ \\
FEV 1 on admission to the ED, Mean \% of the predicted value $\pm \mathrm{SD}$ & \\
Measurement of airflow obstruction in the ED, $\mathrm{n}(\%)$ & $32(86)$ \\
At least one measurement & $28(76)$ \\
One measurement at ED admission & $20(54)$ \\
One measurement before discharge & $16(43)$ \\
One measurement at admission and before discharge & $18 \pm 19$ \\
Mean ED stay \pm SD, $h$ & $12(32)$ \\
Consultation with a respiratory physician in the ED, $\mathrm{n}(\%)$ & \\
\hline
\end{tabular}

FEV ${ }_{1}$ Forced expiratory volume in one second; PEF Peak expiratory flow

was a consultation with a respiratory physician and the mean length of stay in the ED was less than $12 \mathrm{~h}$. For 11 (30\%) patients, the management plan at discharge from the ED was in accordance with four of the seven criteria, namely, the prescription of an ICS at discharge, advice for medical follow-up, measurement of airflow obstruction and asthma education provided in the ED. Airflow obstruction was assessed for 28 (76\%) patients at admission to the $\mathrm{ED}$, but it was reassessed in only $20(54 \%)$ patients at discharge. The proportion of patients that received an adequate prescription for an ICS was $78 \%(\mathrm{n}=29)$.

Thirty-five patients (95\%) received a prescription for an oral corticosteroid at discharge. The prescription was in accordance with the asthma guidelines for $19(51 \%)$ patients (ie, prescribe corticosteroid for patients with an airflow obstruction less than $60 \%$ but do not prescribe corticosteroid if airflow obstruction is greater than $60 \%$ [3]). The prescription was given to 18 of 19 patients who had an airflow obstruction of less than $60 \%$ of the predicted value. For eight patients, an oral corticosteroid was prescribed even though the airflow obstruction was greater than $60 \%$ of the predicted value. Nine patients who did not have a value documented in their medical chart were also prescribed an oral corticosteroid. For 34 (97\%) of the oral corticosteroid prescriptions, the dosage was in accordance with the Canadian asthma guidelines (ie, between $30 \mathrm{mg} /$ day to $60 \mathrm{mg}$ /day equivalent prednisone [3]). It was estimated that patients received a mean dose of $46 \mathrm{mg} /$ day of prednisone. The mean duration of treatment was 8.2 days. For 25 (71\%) patients who received a prescription for an oral corticosteroid, the duration of treatment was between seven and 14 days.

Asthma education was provided to $29(78 \%)$ patients in the $\mathrm{ED}$ in at least one of the following areas: role and side effects of the medication, inhalation technique or triggering factors. Medical follow-up was recommended to $22(60 \%)$ patients. Only $12(32 \%)$ patients were referred to an asthma education centre, and the professionals who made the most referrals were respiratory therapists. If patients were not referred to an asthma education centre in the ED, a referral was provided by the investigators. Therefore, all patients in the study were referred; however, only seven (19\%) visited the asthma education centre.

\begin{tabular}{|c|c|c|}
\hline Conformity criteria & $\%(n)$ & $(95 \% \mathrm{Cl})$ \\
\hline $\begin{array}{l}\text { Criterion 1: Measurement of airway obstruction } \\
\text { before ED discharge }\end{array}$ & $54(20)$ & $(38-70)$ \\
\hline Criterion 2: Prescription of an inhaled corticosteroid & $78(29)$ & $(65-91)$ \\
\hline \multicolumn{3}{|c|}{ Criterion 3: Prescription of an oral corticosteroid $(n=35)$} \\
\hline $\begin{array}{l}\text { For patients who had an } \mathrm{FEV}_{1} \text { or a } \mathrm{PEF}<60 \% \text { of the } \\
\text { predicted value on admission to the } \mathrm{ED}\end{array}$ & $51(19)$ & \\
\hline Prescribed & $48(18)$ & \\
\hline Not prescribed & $3(1)$ & \\
\hline \multicolumn{3}{|l|}{$\begin{array}{l}\text { For patients who had an } \mathrm{FEV}_{1} \text { or a } \mathrm{PEF}>60 \% \text { of the } \\
\text { predicted value on admission to the ED }\end{array}$} \\
\hline Prescribed & $22(8)$ & \\
\hline Not prescribed & $3(1)$ & \\
\hline \multicolumn{3}{|l|}{$\mathrm{FEV}_{1}$ or a PEF not available on admission to the ED } \\
\hline Prescribed & $24(9)$ & \\
\hline Not prescribed & 0 & \\
\hline $\begin{array}{l}\text { Criterion 4: Adequate dosage }{ }^{\dagger}(30 \mathrm{mg}-60 \mathrm{mg} \\
\text { prednisone equivalent) }\end{array}$ & $97(34)$ & $(88-104)$ \\
\hline Criterion 5: Adequate duration of treatment ${ }^{\dagger}(7-14$ days $)$ & $71(25)$ & $(56-86)$ \\
\hline \multicolumn{3}{|l|}{ Criterion 6: Asthma education provided to the patient } \\
\hline Any type of education & $78(29)$ & $(67-91)$ \\
\hline Role and side effects of the medication & $46(17)$ & $(30-62)$ \\
\hline Inhalation technique & $73(27)$ & $(59-87)$ \\
\hline Triggers & $38(14)$ & $(22-53)$ \\
\hline Criterion 7: Medical follow-up recommended & $60(22)$ & $(44-76)$ \\
\hline Conformity to all criteria & $8(3)$ & $(0-17)$ \\
\hline
\end{tabular}

*Adapted from reference 3 ; ${ }^{\dagger}$ For the patients who received a prescription for an oral corticosteroid $(n=35)$. FEV 1 Forced expiratory volume in $1 \mathrm{~s}$; PEF Peak expiratory flow

\section{DISCUSSION}

The present study evaluated the proportion of patients in two tertiary care hospitals with an asthma exacerbation who had a management plan at discharge from the ED that was in accordance with the Canadian asthma guidelines. We found that only three of $37(8 \%)$ patients had a management plan that was in accordance with all seven criteria used from the guidelines. This brings into question the application of these guidelines in clinical practice, even though physicians appear to be knowledgeable and realize the importance of the guidelines (2). Moreover, doctors in the EDs were aware of the study, which may have biased our results towards better conformity to the criteria.

The present study was the first to evaluate the management plan for an asthma exacerbation at discharge from the ED. Other studies have examined the management plan during the stay in the ED. Reid et al (6) conducted a five-month retrospective study in Saskatchewan that included 130 adults (147 visits) from the ED of three tertiary care hospitals to evaluate whether the treatment for the asthma exacerbation in the ED was in conformity with the 1996 Canadian asthma guidelines. A second study by Salmeron et al (7) in France included 3772 adults who were admitted in 37 EDs for an asthma exacerbation. The primary objective of that study was to describe the severity of the asthma exacerbation and to evaluate whether the management plan in the ED was adequate (7). Thus, we can compare only certain results of our study with 
these two studies because they examined the management plan during the ED stay and not at discharge. First, we are able to compare our results regarding the prescription of an ICS and the recommendation for a medical follow-up. In our study, $78 \%$ of patients received a prescription for an ICS compared with $74 \%$ and $50 \%$ for Reid et al (6) and Salmeron et al (7), respectively. This result is encouraging; however, the proportion of patients who received a prescription for an ICS remains suboptimal when considering the efficacy of this therapy. A medical follow-up was recommended for $60 \%$ of the patients in the present study, and only $56 \%$ of these patients consulted their family physician or a respiratory physician in the month following discharge from the ED. This result is comparable with that obtained by Stevens and Gorelick (9), in which 515 children with an asthma exacerbation had a medical follow-up planned in the two weeks following discharge from the ED. In the study by Reid et al (6), a medical follow-up was planned in only $37 \%$ of cases.

In the present study, most patients (95\%) received a prescription for an oral corticosteroid at discharge from the ED, but in only $51 \%$ of the cases was this decision made in accordance with the measurement of airflow obstruction. However, the guidelines state that such a prescription should be considered in all patients who are admitted to the ED for an asthma exacerbation (3). In addition, the criteria regarding the dosage and duration of treatment for an oral corticosteroid appear to be strict, and it is known that an optimal regimen has not been determined. Therefore, a shorter duration of treatment would be appropriate in certain cases. For these reasons, we also calculated an overall conformity rate to the guidelines excluding these three criteria, which was $30 \%$.

Studies (3) have shown the positive impact of medical follow-up and asthma education in terms of improvement in quality of life, adherence to the medication and inhalation technique, as well as a reduction in the severity of asthma, absenteeism from school and work, number of ED or hospital admissions and health care costs. Asthma education was provided to many patients ( $78 \%$ ) in our study; however, it mainly concerned inhalation technique $(73 \%)$ and was less often about the triggering factors of asthma exacerbations (38\%). Although referral to an asthma education centre is not a criteria of the Canadian asthma guidelines, it is strongly recommended (3). Only 32\% of the patients in our study were referred to an asthma education centre, even though the ED visit should be used as an opportunity to target patients who are at risk for further asthma exacerbations. This result could be explained by the workload of the staff in the ED or by the fact that the asthma education centre activities were still unknown to the ED personnel. It was disappointing to find that only $19 \%$ of all patients who were referred (both by the investigators and the ED personnel) attended an appointment at the centre.

Our study adds information about the appropriateness of the management plan at discharge from the ED for an asthma exacerbation and we identified certain aspects of the treatment that are still inadequate. The present study had a few limitations, including a small sample size and lack of standardization of the questionnaires used to collect most of the information. The inclusion of only a small number of patients over a sixmonth period can be explained by the fact that our recruitment only occurred during the day and on weekdays. In addition, many patients were hospitalized $(n=19)$ and others may have consulted emergency clinics surrounding the two hospitals instead of presenting to the busy EDs. Because a small number of patients were included from only two EDs, our results are not generalizable to other EDs in Canada. Finally, our study was not designed to include both an intervention and a control group.

\section{CONCLUSIONS}

In many cases, the management of asthma exacerbations was not in accordance with the 1999 Canadian asthma guidelines. Only $8 \%$ of patients had a management plan in complete agreement with the stated criteria. An insufficient number of patients had a measurement of airway obstruction at discharge, a prescription for an ICS, asthma education, a recommendation for a medical follow-up and patient referral to an asthma education centre. Intervention tools, such has a standardized therapeutic plan (including seamless care considerations) could be implemented to improve the care of these patients $(8,10,11)$.

ACKNOWLEDGEMENTS: The authors would like to acknowledge Drs André Cartier MD FRCP(C) FAAAAI and Manon Labrecque MD MSc FRCP for their contribution to the present project.

FUNDING: Dr Lucie Blais is the endowment Pharmaceutical Chair, AstraZeneca in Respiratory Health and is the recipient of a New Investigator salary support grant from the Canadian Institutes of Health Research. Marie-France Beauchesne is the endowment Pharmaceutical Chair, AstraZeneca in Respiratory Health. The present study received a grant from GlaxoSmithKline through l'Hôpital du Sacré-Coeur de Montréal, Montreal, Quebec.

\section{REFERENCES}

1. National Asthma Control Task Force. The prevention and management of asthma in Canada: A major challenge now and in the future. <www.phac-aspc.gc.ca/publicat/pma-pca00/pdf/ asthma00e.pdf $>$ (Version current at April 15, 2005).

2. Glaxo Wellcome Inc. L'asthme au Canada: Un sondage déterminant. $<$ www.asthmeaucanada.com/manage/execsumm_fr.pdf $>$ (Version current at April 15, 2005).

3. Boulet LP, Becker A, Bérubé D, Beveridge R, Ernst P, for the Canadian Asthma Consensus Group. Canadian Asthma Consensus Report, 1999. CMAJ 1999;161(Suppl 11):S1-61.

4. Krahn MD, Berka C, Langlois P, Detsky AS. Direct and indirect costs of asthma in Canada 1990. CMAJ 1996;154:821-31.

5. Chapman KR, Ernst P, Grenville A, Dewland P, Zimmerman S. Control of asthma in Canada: Failure to achieve guideline targets. Can Respir J 2001;8(Suppl A):35A-40A.

6. Reid J, Marciniuk DD, Cockcroft DW. Asthma management in the emergency department. Can Respir J 2000;7:255-60.

7. Salmeron S, Liard R, Elkharrat D, Muir J, Neukirch F, Ellrodt A Asthma severity and adequacy of management in accident and emergency departments in France: A prospective study. Lancet 2001;358:629-35

8. Collins S, Beilby J, Fardy J, Burgess T, Johns R, Booth B. The national asthma audit. Bridging the gap between guidelines and practice. Aust Fam Physician 1998;27:907-13.

9. Stevens MW, Gorelick MH. Short-term outcomes after acute treatment of pediatric asthma. Pediatrics 2001;107:1357-62.

10. Bailey R, Weingarten S, Lewis M, Mohsenifar Z. Impact of clinical pathways and practice guidelines on the management of acute exacerbations of bronchial asthma. Chest 1998;113:28-33.

11. Petersen DL, Murphy DE, Jaffe DM, et al. A tool to organize instructions at discharge after treatment of ashtmatic children in an emergency department. J Asthma 1999;36:597-603. 


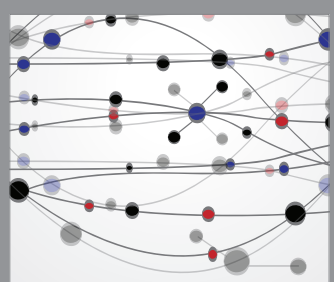

The Scientific World Journal
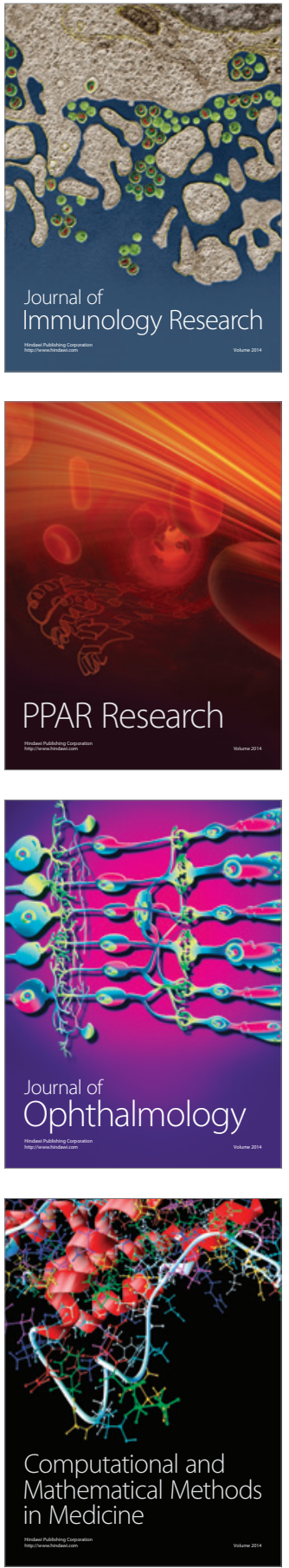

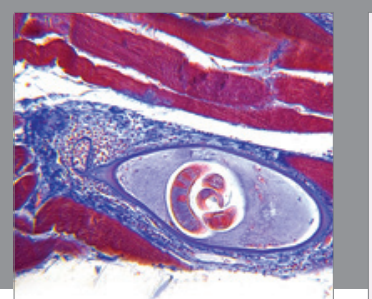

Gastroenterology Research and Practice

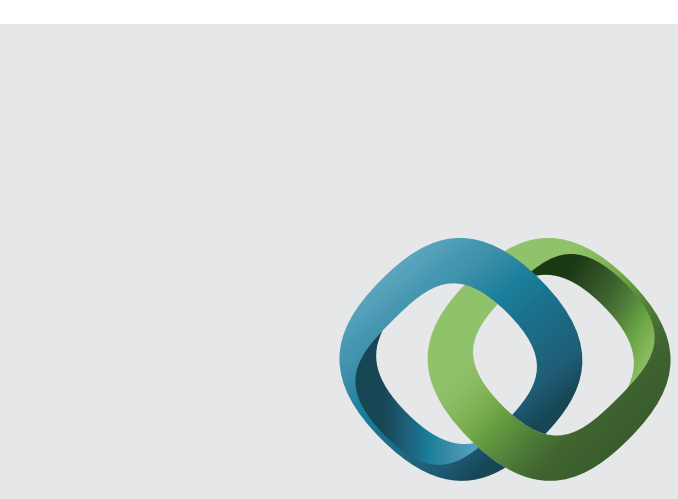

\section{Hindawi}

Submit your manuscripts at

http://www.hindawi.com
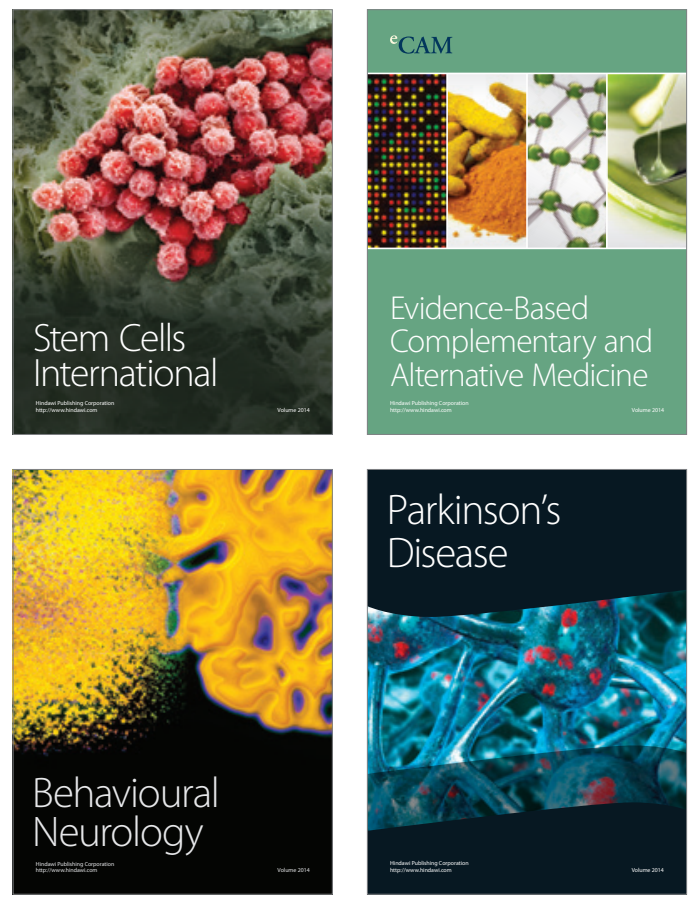
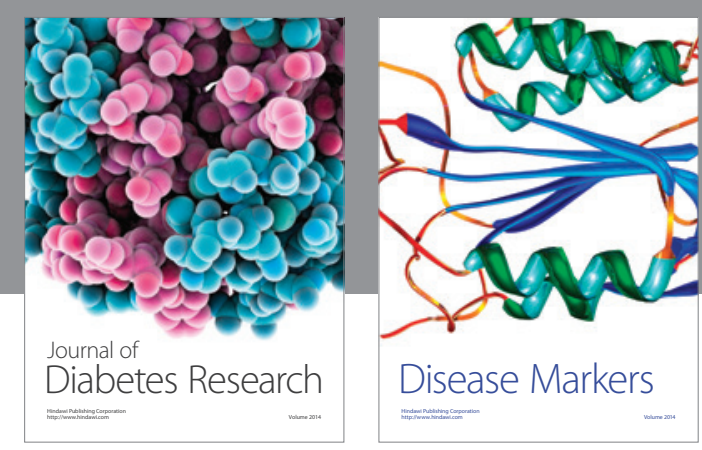

Disease Markers
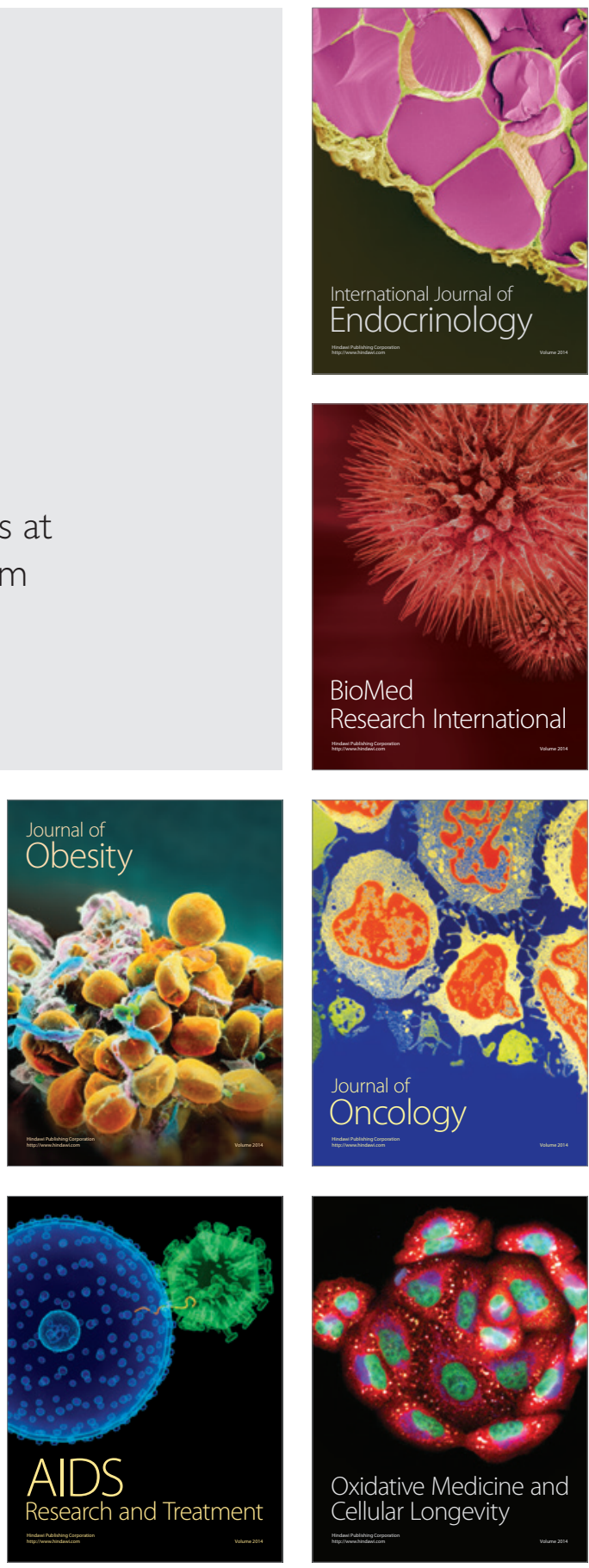